CZU:165+316.344.42

https://doi.org/10.52505/filomod.2021.15.32

\title{
ELITELE COGNITIVE ÎN CRIZA ACTUALĂ A ȘTIINT,ELOR SOCIOUMANE
}

\author{
ION PLĂMĂDEALĂ \\ Institutul de Filologie Română „B. P.-Hasdeu” al MEC
}

Rezumat. Comunicarea va aborda aspecte relevante și de actualitate ale profundei crize epistemice care, în ultimii ani, a pătruns din viața civică și discursul public al societăților occidentale în instituțiile academice, în practic întreg câmpul disciplinelor socioumane. Vor fi evidențiate cauzele principale, anumite manifestări simptomatice ale acestei crize și rolul elitelor cognitive in instaurarea unor monoculturi ideologice ostile științei liberale prin demersuri și concepte de tip ideologic, militant. Dintre acestea din urmă, ne vom referi critic la mișcarea decolonială și ,studiile decoloniale/postcoloniale” asociate și la fenomenul „cancel culture”.

Cuvinte-cheie: Epistemologie, elite cognitive, cenzură, „cancel culture”, libertate academică.

Abstract. The speech will address relevant and current aspects of the deep epistemic crisis that, in recent years, has penetrated from the realm of civic life and public discourse of Western societies into academic institutions - virtually into the entire field of socio-human disciplines. The main causes of this crisis, certain symptomatic manifestations thereof and the role of cognitive elites in establishing ideological monocultures hostile to liberal science through ideological and militant approaches and concepts will be highlighted. Of the latter, we will critically refer to the decolonial movement and the associated decolonial/postcolonial studies and the cancel culture phenomenon.

Keywords: Epistemology, Cognitive Elites, Censorship, Cancel Culture, Academic Freedom.

În continuare ne vom referi succint la criza științelor socioumane în societățile occidentale și câteva manifestări de politizare și ideologizare în războaiele culturale academice. Despre fenomenul de criză, discreditare și corupere a științelor se discută tot mai insistent de la începutul pandemiei Covid-19, context în care dezbaterile au fost subordonate tribalismului, intereselor de grup, autopromovării și etalării ostentatorii a virtuților (virtue signaling). Într-o lucrare recentă cu titlu sugestiv: Ficțiuni științifice. Cum frauda, prejudecata, neglijența și escrocheria subminează căutarea adevărului, Stuart Ritchie conchide că modul defectuos în care este actualmente organizată cercetarea științifică ,îi încurajează pe cercetători să fie obsedați de prestigiu, faimă, finanțare și reputație în detrimentul rezultatelor riguroase și fiabile" (Ritchie, 2020, p. 13). 
Un rol important în discalificarea expertizei științifice și multiplicarea semisavanților în teorii negaționiste și conspiraționiste îl joacă rețelele sociale, care au multiplicat și difuzat virotic scepticismul radical, cinic al epistemologiilor relativiste și constructiviste postmoderne. Toate formele de constructionism, din care s-au inspirat hermeneuticile suspiciunii la care ne vom referi în continuare, împărtășesc o atitudine negativă și iconoclastă, de revizionism și transformare radicală a tuturor valorilor, tradițiilor și instituțiilor democrației liberale. Principiile-cheie ale „teoriei” critice (Theory) postmoderne sunt reificate în pletora actualelor studies care descind din „studiile culturale” (Cultural Studies) ale anilor 1970 și s-au sistematizat un deceniu mai tîrziu: Racial Studies, Post-Colonial Studies, Whiteness Studies, Gay and Lesbian Studies, Fat Studies, Media Studies, Gender Studies etc. Toate acestea, care proliferează în umanități, științe sociale și arte, sunt teorii „critice” în accepțiile neomarxiste ale Școlii de la Frankfurt, adică abordează critic diversele relații de putere dintre categoriile „dominaților” (săracii, femeile persoanele de culoare, minoritățile sexuale) și cele ale „dominanților” (bărbații albi, heterosexuali). 'În studiile postcoloniale sau cele ale globalizării, „oprimații” ilustrează alteritatea exemplară și superioară moral întruchipată, bunăoară la Gyatry Spivac, de către studenții africani și haitieni, în genere de cei colonizați și imigranții care reprezintă figura generică a subalternului (Albrecht, 2013, p. 51); la G. Agamben, aceștia sunt deposedații, în primul rând refugiatul și prizonierul din lagărul de concentrare (Nelon, 2009, p.16); în lucrările cunoscute ale lui Michael Hardt și Antonio Negri creativitatea și biodiversitatea este pusă pe seama tinerilor și exploataților din Sud (ibid., p. 20) etc.

Totuși trebuie menționat că, reunite în etosul marxist al criticii ideologice, toate aceste „studii” postmoderniste deviază de la marxismul clasic nu numai prin focalizarea exclusivă pe cultură și raporturile dintre putere, cunoaștere și limbaj, dar și prin scepticismul cinic privind posibilitatea de a obține o cunoaștere obiectivă. Au luat astfel ființă forme tot mai radicalizate de militantism academic, după care „totul e politic”, „totul e construit social”, o cohortă de ,,academo-militanți” (Heinich, 2021, p. 20), o pătură de ,progresorat” (Abu-Odeh, 2021), care au substituit căutarea adevărului științific cu obiective de inginerie socială, de răsturnare și prefacere revoluționară a societăților liberale.

O altă mențiune utilă este că, deși majoritatea ,academo-militanților” își afișează ascendența teoretică psihanalitică, poststructuralistă sau postmodernistă, distanța care îi separă de Heidegger, Freud, Lacan, Derrida sau Foucault este semnificativă și marchează o tranziție de la o formă teoretică a postmodernismul speculativ, sceptic și ludic la o formă aplicativă, angajată în proiectul reformării lumii. Gânditorii numiţi au pus sub ștergere deconstructivă metafizica logocentrică încorsetată într-o gândire binară, grevată de ambiții totalitariste și teleologice ale raționalității instrumentale și excesele narcisiste ale individualismului dezlănţuit, dar ei nu abandonează 
spiritul dialecticii care menține vie tensiunea dinamică a structurii bipolare fundamentale a ființei. Negativitatea, împinsă de emulii acestora până la limitele scepticismului nihilist, nu-și capătă forța revoluționară decât pe fundalul traditiei contestate, dar și afirmate totodată în gestul reflexiv al criticii; metalimbajul critic este în același timp imposibil, dar și necesar, la fel și judecata normativă și opțiunea etică. Deci suntem în inima unei gândiri aporetice și a dublelor constrângeri cu care ne-a familiarizat arta și literatura modernistă. Pe de altă parte, în tipurile de critică activistă la care ne-am referit, predominante după 2010 , se produce o formă nedialectică de Aufhebung, în care negativitatea urmărește să elimine momentele anterioare din devenire prin inversarea în forță a termenilor binari și suprimarea tradiției și a memoriei cultural-istorice.

Pentru a înțelege originile și cauzele acestor coruperi ideologice ale disciplinelor socioumane, ne putem raporta la sociologia „critică” a lui P. Bourdieu şi binecunoscuta French Theory (J. Derrida, M. Foucault, J. J. Lacan s..a.), la „studiile culturale britanice" marcate de neormaxismul lui St. Hall sau la ,proiectul sacru al sociologiei americane”, care își propune să reformeze societatea pentru a combate inegalitatea, sărăcia, opresiunile în conformitate cu spiritul și legea drepturilor civice, feminismul, marxismul și alte mișcări ,progresiste” (Smith, 2014). La fel, ne putem aminti de rolul important pe care l-au jucat în SUA științele sociale, în special antropologia culturală a lui Franz Boas, în adoptarea legislației antirasiale, a Legii drepturilor civile din 1964, care a devenit a doua constituție a țării și din care ulterior a emanat corectitudinea politică exportată în restul lumii. Azi SUA și-a asumat misiunea de a converti lumea la religia diversitară, în cunoscuta manieră a Cominternului sovietic din perioada războiului rece - „ca depozitar al speranței pentru toți care ar năzui să răstoarne nedreptățile ordinii mondiale" (Caldwell, 2020, p. 143). Punctul comun al tuturor proiectelor hibride de militantism academic care se revendică din teoria critică este deconstrucția, „decolonizarea”, iar în fapt abolirea culturii occidentale și înlocuirea ei cu o "hegemonie culturală” (A. Gramsci) a grupurilor „oprimate” constituite strict pe identități imutabile sau esențializate: rasă, sex, gen, etnie, religie etc.

Cauzele profunde ale subordonării descrierilor științifice și judecăţilor de valoare deopotrivă la ideologii militante, identitare sau la acte subiective de natură afectivă și morală trebuie căutate în împletirea tot mai strânsă a moralităţii cu politicul. În special după 1960, un moralism politic tot mai accentuat și sentimentalizat mobilizează energiile nenumăratelor mișcări și facțiuni emancipatoare ce își propun să eradicheze răul din lume, nedreptatea socială prin schimbarea legilor și instituțiilor liberale strâmbe conform unor concepții diferențiate ale justiției sociale: justiţia feministă, justiția neagră, justiția sharia, justiția postcolonială ș.a. Obiectivul major al acestor proiecte idealiste de inginerie socială este ameliorarea condiției a trei categorii de oameni întruchipate de figura abstractă a celui sărac, 
celui vulnerabil și a celui exclus folosite pe rol de incriminare a orânduirii burgheze detestate. Atitudinea etică cerută este părăsirea individualismului vieții morale și răscumpărarea vinei Europei pentru păcatele istorice legate de sclavagism, războaie coloniale ș.a. Se cultivă, inclusiv prin educația de toate treptele, o conștiință vinovată, ,oikophobia”, termen prin care Roger Scruton a diagnosticat sindromul urii față de casa natală și propria cultură (R. Scruton, 2004 p. 36). Contrar eticilor liberale centrate pe individul autonom, sursa imperativelor morale este localizată în cerințele altor persoane, iar centrul responsabilității e delegat către instanțe colective. Concepția etică a lui Lévinas este radicalizată prin mistificarea alterității Celuilalt - o altă pietate a discursului postmodernist și multiculturalist prin care se privilegiază asimetric un grup particular ce își asumă autoritate morală asupra celorlalți și multiple drepturi fără îndatoririle aferente.

Prin figurile sacerdotale ale modernității intelectuale, cu Nietzsche și Freud în capul listei, Occidentul intrase definitiv în epoca suspiciunii caracterizată printr-o căutare neostoită a motivațiilor inconștiente, ascunse îndărătul reprezentărilor iluzorii, o demistificare a tot și a toate. Virusul îndoielii și scepticismului se va propaga endemic în tot corpul cunoașterii socioumane dominate de principiul construcționist după care tot ce apare ca fiind „natural”, în firea lucrurilor, este de fapt un efect al proceselor și practicilor sociale, că toate realitățile sociale și semiotico-simbolice sunt efecte ale relațiilor de putere, iar miza demascării ideologice devine eliberarea celor oprimați. Stuart Hall, părintele amintit al studiilor culturale britanice, stipulează expres că interesul constitutiv al acestora se află în legătura dintre reprezentări și putere (Hall, 1996, p. 40).

Imperativele de corelare a cercetării cu agendele politice au devenit repede norme nescrise ale vieții academice și condiții obligatorii pentru promovarea profesională, iar orice încercare de a experimenta niște metode mai empirice decât discursul poststructuralist sau de a interoga injoncțiunile teoriilor „critice” este taxată dur de comunitatea academică afiliată practic in corpore la stângismul cultural. Și astfel respectiva paradigmă s-a transformat în ortodoxie dominantă pentru tinerii cercetătorii obligați să deconstruiască, interogheze și să vorbească în idiomul lui M. Foucault sau P. Bourdieu. În general, trebuie menționat că ambiția emancipatoare a criticii literare focalizate pe analiza formelor de inegalitate și dominare s-a dovedit un eșec, inclusiv din cauza logicii binare, a partizanatului ideologic și a refuzului de a dezbate dezacordurile politice reale.

Conversiunea suspiciunii și scepticismului într-un limbaj vernacular a dus la efecte distrugătoare asupra vieții comunale și colective, subțiind drastic capitalul încrederii și solidarității sociale între clase, inspirând tendințe revoluționare în cuprinsul Europei, fracturând corpul politic și întețind discordiile ideologice. Aceste fenomene sunt catalogate la rubrica de „,culture wars”, termen care s-a extins din lumea anglo-saxonă în întreaga Europă. Promovate de elitele intelectuale, artistice și mediatice, războaiele 
culturale au erodat din interior toate instituțiile statului, narațiunile și imaginarul național, instaurând un regim de gândire unică și o poliție a limbajului care înăbușă orice dezbatere intelectuală autentică.

Fascinația elitelor occidentale pentru marxism și toate regimurile totalitare comuniste din secolul trecut, precum și referința lui Ch. Caldwell la Comintern ne evocă butada atribuită lui Lenin că intelectualii care fac dezinteresat apologia bolșevismului sunt niște „,idioți utili”.

Deja după 1995, când în SUA au fost desecretizate fișierele Venona și alte dosare a ieșit la iveală în mod surprinzător cât de masiv se infiltrase agentura de influență stalinistă în toate structurile statelor occidentale, în organizațiile internaționale postbelice de tip ONU și UNESCO, în partidele de orientare social-democrată și în așa-numita „mișcare liberală progresistă și antifascistă" ce constituie actualmente mainstream-ul mediilor universitare de pe ambele maluri ale Atlanticului.

Un caz simptomatic pentru forma excesivă de politizare și moralizare a cercetărilor în discursurile socioumane aservite cauzelor militante ale politicilor identitare: într-un studiu despre dragostea postmodernă, Caterine Belsey, cunoscută cercetătoare literară britanică, după ce subliniază că deține o bună cunoaștere a romanului Beloved de Toni Morrison, se eschivează de la interpretarea acestuia invocând mai multe justificări. Că ,„̂i este teamă" (să reținem acest cuvânt, teamă, care denotă aici un sentiment moral) „să nu se creadă că ar coloniza opera acesteia" și că ar putea prin propria interpretare să invalideze lucrările colegelor afro-americane. Și deoarece Morrison descrie „exproprierea albă a experienței negre, îmi e teamă, declară Belsey, ca nu cumva să repet acest proces", printr-o ingerință în aria bătătorită de feministele afro-americane, la fel cum bărbații, adaugă ea moralizator, nu ar trebui să se pronunțe despre feminismul critic. Pentru că în toate aceste cazuri, insistă Belsey, problema este de ordin politic, „nu de cunoaștere sau de experiență, ci politic" (Belsey, 1994, p. 702-703]. Acest gen de atitudine poate fi catalogat drept o capitulare morală și intelectuală explicabilă în contextul de răsturnare civilizațională și culturală operată actualmente de mișcările „woke”, „,cancel culture” și „studiile academice recriminatorii" (Lindsay et all. 2018).

Radicalismul amintit e prezent în dozaje diferite în întreprinderea magistrală a intelighenției occidentale de a-și împăca conștiința vinovată și regăsi mântuirea fie prin integrarea în valorile calde ale unor totalități comunitare, fie prin ameliorarea condiției celui sărac, vulnerabil, marginalizat și nedreptăţit.

Din aceleași asumpții la care subscrie tacit și Belsey în pasajul citat, se consideră că un alb nu-l poate înțelege pe un negru, bărbatul pe femeie, creștinul pe musulman, heterosexualul pe homosexual, mai grav, însăși pretenția de înțelegere comună, universală, care ar depăși contingențele de ordin cultural, ar masca o intenție de dominare și asimilare. De unde, concluzia acestor sofisme impune adoptarea de politici identitare, de 
recunoaștere și politici de prezervare cu orice preț a identităților culturale construite de antropologii angajaţi. Trebuie menționat că toate aceste evoluții spectaculoase și efecte perverse nu pot fi înțelese doar din perspectiva unor analize conceptuale, filosofice, iar antropologia culturală se dovedește neputincioasă nu numai din cauza angajamentelor sale ideologico-politice, dar și a limitelor disciplinare.

Un efect direct și cel mai important al activismului politic asupra criticii a fost reorientarea acesteia dinspre hermeneutică către retorică, la care a contribuit masiv și critica postmodernistă a reprezentării, care este implicit o critică a hermeneuticii. Conceptul central în această mutație nu mai este sensul, reprezentarea, ci performanța și termenii sateliți precum performativ, performativitate, răspunsul de lectură etc. În discursul de acceptare a premiului Nobel pentru literatură, din 1993, Toni Morison a ținut să reabiliteze ideea bartheziană conform căreia: „limbajul opresiv nu doar reprezintă violența, ci el este violență" (Morrison, 2019, p. 12). Deci ea reiterează aceeași eroare de a confunda ,a fi” cu ,a acționa”, considerând că existența este funcție a acțiunii, și eroarea de a echivala acțiunea locutorie, adică enunțurile performate, cu indivizii umani liberi ce comit agresiuni asupra altor persoane. Deci în noul Zeitgeist, întrebarea tradițională „,e semnifică textul?” e înlocuită sau subsumată întrebării: „,ce face textul?", ceea ce contează este poziționarea subiectului în raport cu semnificantul material al textului, modul folosirii acestuia în interacțiunea socială. Respectiv întrebarea ,în ce crezi, care este adevărul convingerii tale?" devine irelevantă în raport cu întrebarea „cine ești?”, ideologia este înlocuită prin identitate, precum procedează Judith Butler în Gender studies și ulterior în Excitabile Speech, în care chestiunea identității și a poziționării cititorului și scriitorului devin prioritare.

În acest spirit al vremii dominat de neopragmatism și activismul cultural-politic, textul literar, din punct de vedere epistemologic, nu deține semnificații proprii, totul e determinat de uzurile la care îl supune destinatarul, respectiv problema interpretării nu se mai pune, iar conflictele de interpretare devin conflicte de forță, care sunt rezolvate printr-o impoziție autoritară a sensului, precum declarase cu franchețe și consecvență logică Foucault.

George Orwell afirma că cine controlează trecutul controlează și prezentul. Întrebarea este dacă dezmembrarea lui Orfeu, în extazul dionisiac al științei vesele deconstrucționiste sau în puritanismul ideologic al științei angajate ce ne somează să nu jelim morții și să dăm uitării trecutul, va fi urmat de rememorarea, reasamblarea organelor sfâșiate ale poetului în gestul recuperator și întregitor al hermeneuticii încrederii. Dubla constrângere aporetică este aici fie să devenim amnezici, dar plini de vitalitate zburdalnică și lipsită de griji, fie să întoarcem privirea înapoi pentru a ne aminti de întregul ființei pe care l-am trăit cândva în iubire, dar înfruntând astfel riscul de a ne preface în stană de piatră. 


\section{Referințe bibliografice:}

1. ABU-Odeh, Lama Abu Odeh. Georgetown's Cultural Revolution [citat 1.09.2021]. Disponibil: https:/quillette.com/2021/04/09/georgetowns-culturalrevolution/.

2. ALBRECHT, Monika. Comparative Literature and Postcolonial Studies Revisited. Reflections in Light of Recent Transitions in the Fields of Postcolonial Studies. In: Comparative Critical Studies, 2013, nr. 10.1, p. 47-65.

3. BELSEY, Catherine. Postmodern Love: Questioning the Metaphysics of Desire. In: New Literary History, 1994, Vol. 25, No. 3, 25th Anniversary Issue (Part 1), p. 683-705.

4. CALDWELL, Cristopher. The Age of Entitlement: America Since the Sixties. New York, 2020.

5. HALL, Stuart. Culture and Power. In: Radical Philosophy, 1996, p. 24-41.

6. HEINICH, Nathalie. Certains chercheurs font croire qu'une bouillie militante serait de la science. In: Le Figaro, 2021, 25 mai.

7. LINDSAY, J., BOGHOSSIAN P., PLUCKROSE, H. Academic Grievance Studies and the Corruption of Scolarship [citat 11.08. 2021]. https://areomagazine.com/ 2018/10/02/academic-grievance-studies-and-the-corruption-of-scholarsh 8 . MORRISON, Toni. Rebelle et Nobel. In: Le Figaro, 2019, 7 août.

9. NELON, Chrisopher. Reading on the Left. In: Representations, 2009, p. 22-50.

10. RITCHIE, Stuart. Science Fictions. How Fraud, Bias, Negligence, and Hype Undermine the Searche fot Truth. New York, 2020.

11. SCRUTON, Roger. England and the Need for Nations. London, 2004.

12. SMITH, Christian. The Sacred Project of American Sociology. Oxford, 2014.

Notă: Articolul a fost realizat în cadrul proiectului de cercetare 20.80009.1606.03 Contexte socioculturale autohtone şi interconexiuni europene în creaţia populară şi literatura cultă din Basarabia (sec. XIX până în prezent), Institutul de Filologie Română „B. P.-Hasdeu” al MEC. 